STUDI

FRANCESI

\section{Studi Francesi}

Rivista quadrimestrale fondata da Franco Simone

165 (LV | III) | 2011

LA RAPPRESENTAZIONE DELLA MADRE NELLA

LETTERATURA FRANCESE DEL NOVECENTO a cura di Dario Cecchetti e Michele Mastroianni

\title{
Paul Verlaine, Romances sans paroles, suivi de Cellulairement
}

\author{
Ida Merello
}

\section{OpenEdition \\ Journals}

Edizione digitale

URL: http://journals.openedition.org/studifrancesi/5090

DOI: 10.4000/studifrancesi.5090

ISSN: 2421-5856

Editore

Rosenberg \& Sellier

Edizione cartacea

Data di pubblicazione: 1 décembre 2011

Paginazione: 665

ISSN: 0039-2944

Notizia bibliografica digitale

Ida Merello, «Paul Verlaine, Romances sans paroles, suivi de Cellulairement», Studi Francesi [Online], 165 (LV | III) | 2011, online dal 30 novembre 2015, consultato il 08 janvier 2021. URL: http://

journals.openedition.org/studifrancesi/5090 ; DOI: https://doi.org/10.4000/studifrancesi.5090

Questo documento è stato generato automaticamente il 8 janvier 2021.

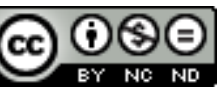

Studi Francesi è distribuita con Licenza Creative Commons Attribuzione - Non commerciale - Non opere derivate 4.0 Internazionale. 


\title{
Paul Verlaine, Romances sans paroles, suivi de Cellulairement
}

\author{
Ida Merello
}

\section{NOTIZIA}

PAUL VERLAINE, Romances sans paroles, suivi de Cellulairement, éd. critique d'Olivier BIVORT, Paris, Livre de Poche Classiques, pp. 383.

1 Questa riedizione, che riprende quella del 2002 del medesimo curatore, comporta sostanziali novità nella definizione del testo, grazie agli apporti della bibliografia più recente. L'impostazione filologica resta tuttavia analoga: per le Romances sans paroles, Bivort continua a basarsi sul testo dell'edizione originale (Sens, 1874), operando delle varianti in base alle osservazioni fatte da Verlaine a margine del testo, ma rifiutando l'ultima edizione in vita dell'autore, del 1891, in quanto emendata di epigrafi significative, con versi dal senso modificato e una disposizione tipografica in grado di alterare il valore espressivo della prima suddivisione strofica. Tuttavia, per il quadro complessivo delle varianti Bivort ha potuto stavolta avvalersi della collazione di manoscritti raccolti in dossier da S. Murphy, J. Bonna e J.-J. Lefrère (Champion 2003), continuando a tener conto, come nella prima edizione, anche delle versioni inviate da Verlaine agli amici (per la maggior parte a Emile Blémont), e conservate nella corrispondenza presso la Bibliothèque Nationale. Le maggiori novità si trovano tuttavia nell'edizione di Cellulairement: nel 2002 il curatore aveva a disposizione solo l'edizione di Steinmetz (1992), fondata sulle indicazioni di Dupuy circa i titoli, le epigrafi, le date di composizione dei testi che Verlaine voleva inseriti nella raccolta, e confrontata con $i$ manoscritti rimasti che presentano varianti ai testi in passi di corrispondenza e in frammenti ricopiati; mentre per la nuova edizione ha potuto consultare per la prima volta il manoscritto acquistato dal Musée des Lettres et manuscrits di Parigi nel 2004. Ci troviamo così di fronte alla prima edizione a stampa del manoscritto di Parigi; e dal confronto serrato con gli altri manoscritti incompleti a disposizione emergono nuove congetture riguardo alle lacune, nell'ambito di un rigoroso lavoro filologico di 
definizione dell'iter testuale. Non dimenticando che si tratta in ogni caso di un'edizione «de poche», Bivort accompagna i testi con un'ampia e importante introduzione sostanzialmente invariata (cfr. "Studi francesi» $n^{\circ} 138$, p.731)-e con una serie minuziosa di note di valido aiuto anche per un pubblico scolare, a loro volta aggiornate tenendo presente in particolare l'edizione della Correspondance générale di Verlaine uscita nel 2005 per opera di Michael Pakenham. 